\title{
Diagnosis of constipation in family practice
}

\author{
Simon Ferrazzi $\mathrm{MSc}^{1}$, Grant W Thompson $\mathrm{MD}^{2}$, E Jan Irvine $\mathrm{MD}^{3}$, Pierre Pare $\mathrm{MD}^{4}$, \\ Laureen Rance PharmD ${ }^{1}$
}

S Ferrazzi, GW Thompson, EJ Irvine, P Pare, L Rance. Diagnosis of constipation in family practice. Can J Gastroenterol 2002;16(3):159-164.

BACKGROUND: Patients who complain of constipation to their family doctor may not be truly constipated. Variability in stool frequency and consistency, and perception of symptoms may lead to inaccurate patient reporting or diagnosis of constipation. OBJECTIVES: To determine whether patients visiting their family doctor with a complaint of, or diagnosed with, constipation fulfilled the Rome II criteria for functional constipation and had stool characteristics of constipation.

METHODS: A random sample of Canadian family physicians were recruited to enroll a series of adults who complained of, or had received a diagnosis of, constipation during an office visit. Patients were advised of the survey. Those providing written consent were contacted by an independent research firm and forwarded a survey questionnaire that included the Rome II gastrointestinal questionnaire, questions regarding their medical history and questions regarding their demographics. Patients also completed a four-week daily diary recording their bowel habits using the Bristol Stool Form Scale, medication use and satisfaction with treatment. Questionnaire and diary responses were retrieved by telephone.

RESULTS: One hundred eighty-four family physicians enrolled 311 patients, of whom 220 completed the questionnaire. Females comprised $79.5 \%$ of the sample and had a mean age of 54.2 years (males 61.6 years; $\mathrm{P}<0.05$ ). According to the Rome II criteria, $37.3 \%$ had functional constipation and $46.8 \%$ had irritable bowel syndrome (IBS). Whole gut transit times estimated using the Bristol Stool Scale were similar among those with self-reported constipation, those with Rome II functional constipation and those with Rome II IBS ( $79.3 \mathrm{~h}, 85.8 \mathrm{~h}$ and $77.4 \mathrm{~h}$, respectively). Almost half of the patients with IBS or functional constipation were taking a pain medication, while nearly one-fifth took antidepressants. Of the medications or remedies taken to treat constipation, patients rated $49.8 \%$ of the doses as satisfactory.

CONCLUSIONS: A large proportion of Canadian primary care patients whose presenting complaint or diagnosis was constipation satisfied the Rome II criteria for IBS, with a smaller number defined as functionally constipated. IBS patients tended to be younger than those with functional constipation, and whole gut transit times did not differentiate IBS from functional constipation. Careful questioning of patients who complain of constipation may reveal constipating medication, diarrhea symptoms or IBS.

Key Words: Bristol Stool Form Scale; Constipation; Irritable bowel syndrome; Rome II; Transit time

Résumé à la page suivante

${ }^{1}$ Health Economics, Janssen-Ortho Inc, Toronto, Ontario; ${ }^{2}$ Department of Medicine, University of Ottawa, Ottawa, Ontario; ${ }^{3}$ Department of Medicine, McMaster University, Hamilton, Ontario; ${ }^{4}$ Professor of Medicine, Laval University, Quebec City, Quebec

Correspondence and reprints: Mr Simon Ferrazzi, Janssen-Ortho Inc, 19 Green Belt Drive, Toronto, Ontario M3C 1L9.

Telephone 416-382-4866, fax 416-449-2658, e-mail sferrazz@joica.jnj.com

Received for publication October 11, 2001. Accepted December 12, 2001 


\section{Le diagnostic de constipation en médecine générale}

CONTEXTE : Les patients qui consultent leur médecin de famille pour de la constipation peuvent ne pas en souffrir véritablement. La variabilité quant à la fréquence et à la consistance des selles ainsi que la perception des symptômes peuvent aboutir à des descriptions inexactes de malaises ou à des diagnostics erronés de constipation.

OBJECTIF : Vérifier si les patients qui consultent leur médecin de famille pour de la constipation ou chez qui un diagnostic de constipation a été posé satisfont aux critères de Rome II relatifs à la constipation fonctionnelle et présentent les caractéristiques définies pour les selles.

MÉTHODE : Un certain nombre d'omnipraticiens ont été choisis au hasard, au Canada, pour inscrire à l'étude des patients qui se plaignaient de constipation ou chez qui un diagnostic de constipation avait été posé au cours d'une consultation. Les patients ont été informés de l'enquête. Ceux qui ont fourni un consentement écrit ont d'abord été appelés par un cabinet spécialisé en recherches, puis ont reçu un questionnaire comprenant le questionnaire sur les troubles gastro-intestinaux définis selon les critères de Rome II, de même que des questions sur leurs antécédents médicaux et des données démographiques. On a également demandé aux patients de noter, dans un registre quotidien, les troubles du transit ense servant de la Bristol Stool Form Scale, leurs médicaments et leur degré de satisfaction à l'égard du traitement, et ce, durant quatre semaines.
RÉSULTATS : Cent quatre-vingt-quatre omnipraticiens ont inscrit 311 patients, dont 220 ont rempli le questionnaire. Les femmes formaient $79,5 \%$ de l'échantillon et étaient âgées en moyenne de 54,2 ans (hommes : 61,6 ans; $\mathrm{P}<0,05$ ). Selon les critères de Rome II, 37,3 \% des sujets souffraient de constipation fonctionnelle et $46,8 \%$, du syndrome du côlon irritable (SCI). Le temps de transit intestinal évalué approximativement à l'aide de la Bristol Stool Form Scale était à peu près le même pour les patients souffrant de constipation auto-déclarée, de constipation fonctionnelle ou du SCI définis selon les critères de Rome II (79,3 h; $85,8 \mathrm{~h}$ et $77,4 \mathrm{~h}$ respectivement). Presque la moitié des patients atteints du SCI ou de constipation fonctionnelle prenaient des analgésiques et presque un cinquième, des antidépresseurs. Quant au degré de satisfaction à l'égard des médicaments ou des remèdes prescrits, 49,8 \% des doses ont été jugées satisfaisantes.

CONCLUSION : Une grande proportion de patients ayant consulté un médecin de premier recours au Canada pour de la constipation ou chez qui un diagnostic de constipation a été posé satisfont aux critères de Rome II relatifs au SCI, mais un nombre moindre de sujets sont considérés comme atteints de constipation fonctionnelle. Les patients souffrant du SCI sont en général plus jeunes que ceux qui souffrent de constipation fonctionnelle, et le temps de transit intestinal ne permet de différencier la première affection de la seconde. La conduite d'une anamnèse méticuleuse chez les patients qui consultent pour de la constipation peut révéler une étiologie médicamenteuse, des symptômes diarrhéiques ou le SCI.
$\mathrm{C}$ onstipation is a common chronic gastrointestinal complaint and, although not life-threatening, is physically and mentally troublesome for many patients (1). In population-based surveys, prevalence rates vary according to the definition used (2,3). For example, in one Canadian survey, $27.2 \%$ of subjects' self-reported that they had constipation, yet only $14.9 \%$ fulfilled the Rome II criteria for functional constipation (FC) (3). The same study showed that $34 \%$ of 312 subjects who had self-reported constipation in the previous three months had seen a physician for it at some time in their lives. In the United States, statistics indicate that physician visits for constipation average 2.5 million per year (4). Rates from the Canadian survey (3) and from Statistics Canada figures (5) for those aged 15 years or older (24.8 million) suggest that approximately 2.3 million Canadians will eventually see a physician for a primary complaint of constipation.

Many people who claim to be constipated in population surveys do not actually fulfill the Rome criteria for FC $(2,3)$. Most also have normal intestinal transit time, based on stool form (2). These observations suggest that patients seen in family practice who complain of, or are given a diagnosis of, constipation might actually suffer from a variety of other functional bowel disorders such as irritable bowel syndrome (IBS). It is important to distinguish FC from IBS because these two conditions have different investigative and treatment algorithms.

The main objective of the present study was to determine the proportion of patients seen in primary care who were thought to have constipation, and subsequently fulfilled the Rome II criteria for FC or IBS. Their symptoms, comorbid disease and medication use were also assessed. Finally, whole gut transit times (WGTTs) were estimated based on stool form scale entries in a daily diary (6-11).

\section{MATERIALS AND METHODS}

\section{Physician recruitment}

An independent research firm generated a random list of 2000 Canadian family physicians, who were invited by letter to recruit patients for a constipation survey. Those willing to participate were forwarded an enrolment package containing the necessary materials (protocol, patient consent forms, physician guide, survey questionnaire and diary for reference).

\section{Subject enrolment}

Eligible subjects were male or female, 18 years of age or older, and had complained of constipation or been given a diagnosis of constipation by their family physician. Patients were advised of the survey and, if willing to participate, provided written, informed consent. A member of the physician's office then notified the independent research firm. A Canadian medical ethics review board (Optimum Clinical Research Inc, Oshawa, Ontario) approved the study.

\section{Subject contact}

Within three days of receiving consent, the research firm contacted the subjects, explained the survey to them, confirmed their involvement and advised them that they would receive a questionnaire together with a four-week diary. Subjects were assured of confidentiality and provided with a toll-free number to call if they had any questions. 


\section{Data collection}

Due to the sensitive nature of some of the survey questions, a telephone/mail/telephone method permitted data to be collected by numeric response, prompted by page and question number. This method was used successfully in a previous study to optimize subjects' comfort levels (3). Participants were contacted weekly in four subsequent telephone calls. The first call collected responses to the questionnaire and the results for the first week of the diary. The remaining calls retrieved diary data from weeks 2 to 4 .

\section{Questionnaire}

The survey questionnaire took approximately $20 \mathrm{~min}$ to complete and included the following items.

- The Rome II Gastrointestinal Questionnaire (12)

- Self-reported constipation-related questions

Definition of self-reported constipation:

- Have you felt constipated in the past 12 months? (Yes or No)

- Have you felt constipated in the past three months?

(Yes or No)

- Questions regarding medications used to treat constipation and level of satisfaction with these medications

- A list of medical conditions commonly associated with constipation

- Questions regarding patient demographics

No material or financial incentive was provided to the subject.

\section{Diary}

Participants were asked to complete a four-week daily diary and include the following information.

- Use of medication and diet supplements. Patients recorded the medications or remedies that they used to treat their constipation. Their satisfaction with each was assessed through the following scale: $1=$ very dissatisfied, $2=$ somewhat dissatisfied, $3=$ neither satisfied nor dissatisfied, $4=$ somewhat satisfied and $5=$ very satisfied.

- Bristol Stool Form Scale. Patients were prompted to record the date and time of every bowel movement and to rate the form of each stool using the following seven-point scale (8).

1. Separate hard lumps, like nuts (hard to pass)

2. Sausage shaped but lumpy

3. Like a sausage but with cracks on its surface

4. Like a sausage or snake, smooth and soft

5. Soft blobs with clear-cut edges (passed easily)

6. Fluffy pieces with ragged edges, a mushy stool

7. Watery, no solid pieces; entirely liquid

\section{Gut transit times}

The Bristol Stool Form Scale, in which stools are scored according to cohesion and surface cracking, correlates well with the WGTT measured by radio-opaque markers $(\mathrm{r}=-0.77, \mathrm{P}<0.001$, a lower score means a longer WGTT $)$ and is responsive to a change in transit time with an alteration in diet $(7,9)$. WGTT was estimated from data from the Bristol Stool Form Scale by using the following formula, previously derived and validated by multiple logistic regression analysis (10):

Females: WGTT $=103-1.23(\mathrm{DF})-4.69(\mathrm{SFS})+0.638(\mathrm{IDTI})$

Males: WGTT $=79-1.33(\mathrm{DF})-1.88(\mathrm{SFS})+0.329(\mathrm{IDTI})$

where DF is the defecation frequency per week, SFS is the stool form score (the sum of three stool form numbers) and IDTI is the mean interdefecatory time interval.

The WGTT has been shown to correlate with markerdetermined transit time in women $(\mathrm{r}=0.74)$ and men $(\mathrm{r}=0.54)(10)$. The normal WGTT for women aged 50 to 59 years was defined as $59.4 \mathrm{~h}$ (SD $21.6 \mathrm{~h}$ ) and 'slow transit' as more than 2 SD above normal (longer than $102 \mathrm{~h}$ ). The normal WGTT for men aged 60 to 69 years was defined as $53 \mathrm{~h}$ (SD 11.7) and 'slow transit' as more than $2 \mathrm{SD}$ above normal (longer than $76 \mathrm{~h}$ ) (10). Transit times were calculated for weeks 1 and 4 of the diary.

\section{Translation}

Two independent linguists translated the survey (questionnaire and diary) from English into Canadian French. These versions were compared and harmonized into one document (forward version), which was then back-translated to English by two different translators. The documents were compared to identify discrepancies from the original version, and the French questionnaire was modified accordingly.

\section{Statistics}

Frequency and proportions are reported with comparison of categorical variables using a $\chi^{2}$ statistic or Fisher's exact test. Data were analyzed using SAS software (version 6.12, SAS Institute Inc, USA), and $\mathrm{P} \leq 0.05$ was considered statistically significant, with adjustment in situations of multiple comparisons.

\section{Subjects}

\section{RESULTS}

Of the 2000 family physicians invited to participate in the study, 184 (9.2\%) agreed to participate, 12 withdrew and 94 enrolled no subjects during the three-month recruitment period. Of the 311 consenting subjects, 220 completed the survey questionnaire, and 211, 203, 202 and 198 completed weeks 1 to 4 of the diary, respectively. Less than $3 \%$ of cases had a structural problem or systemic disease that could possibly have accounted for their constipation. 
TABLE 1

Demographic features of patients who satisfied the Rome Il criteria for irritable bowel syndrome (IBS) or functional constipation (FC)

\begin{tabular}{lccc}
\hline & $\begin{array}{c}\text { Total } \\
\text { (n) }\end{array}$ & $\begin{array}{c}\text { Rome II } \\
\text { IBS (\%) }\end{array}$ & $\begin{array}{c}\text { Rome II } \\
\text { FC (\%) }\end{array}$ \\
\hline $\begin{array}{l}\text { Overall } \\
\text { Sex }\end{array}$ & 220 & 46.8 & 37.3 \\
$\quad$ Male & 45 & 40.0 & 33.3 \\
$\quad$ Female & 175 & 48.6 & 38.3 \\
Age (years) & & & \\
18-34 & 26 & 57.7 & 19.2 \\
35-49 & 55 & 54.6 & 32.7 \\
50-64 & 61 & 50.8 & 34.4 \\
$\quad$ 64 & 78 & 34.6 & 48.7 \\
Region & & & \\
$\quad$ Atlantic & 20 & 35.0 & 35.0 \\
Quebec & 25 & 48.0 & 32.0 \\
$\quad$ Ontario & 77 & 44.2 & 41.6 \\
Prairie provinces & 43 & 46.5 & 39.5 \\
British Columbia & 55 & 54.6 & 32.7 \\
\hline
\end{tabular}

*Strong association between age and IBS or $F C(P=0.053$ and $P=0.034$, respectively)

Questionnaire

Females comprised $79.5 \%$ of the sample and had a mean age of $54.2 \pm 17.2$ years, compared with $61.6 \pm 15.8$ years for males $(\mathrm{P}<0.05)$. Of the 220 participants, 200 (90.9\%) selfreported constipation in the past 12 months and 196 $(89.1 \%)$ self-reported constipation in the past three months. According to the Rome II questionnaire and algorithms, $46.8 \%$ of the patients were found to have IBS and $37.3 \%$ were found to have FC. The remaining $15.9 \%$ had neither of these diagnoses.
The demographic features of those with IBS or FC are outlined in Table 1 . There were no differences between the sexes; however, there was a strong association $(\mathrm{P}<0.05)$ between age and IBS or FC, with most of the younger patients having IBS (51\% to $58 \%$ ) and those over aged 64 years tending to fulfill criteria for FC (48.7\%). The mean age of people with IBS was 52.3 years (SD 16.7 years) compared with 59.9 years (SD 16.5 years) for those with FC $(\mathrm{P}<0.05)$. There were no significant differences with regard to household income, employment status or level of education between those with IBS and those with FC.

The symptoms of diarrhea that serve to distinguish IBS from FC are shown in Table 2. The following symptoms were significantly more common in people with IBS: abdominal fullness, bloating or swelling; having to rush to a toilet to have a BM; loose, mushy or watery stools; and passing mucus during a $\mathrm{BM}$.

Nearly half of both the IBS and FC patients were taking pain medications (Table 3), and $10.7 \%$ of IBS and $8.5 \%$ of FC patients were taking both analgesics and antidepressants. Cancer was similarly common in both disorders. Thirteen of the 16 cancer patients were treating their constipation with a medication, or a herbal or homeopathic remedy.

Of the 200 patients self-reporting in the past 12 months, $86.5 \%$ used a medication, or a herbal or homeopathic remedy to treat their constipation during the previous year. Of these 173 subjects, $59.5 \%$ had been attempting to treat their constipation for more than one year. Of those selfreporting constipation in the past three months $(n=196)$ $25.5 \%$ had been told by a doctor that a medication or other illness was causing their constipation (males $32.4 \%$ and females $23.9 \%$ ). The use of medications, or herbal or homeopathic remedies to treat constipation was reported in $77.7 \%$ of IBS and $65.9 \%$ of FC patients.

TABLE 2

Symptoms experienced at least one-quarter of the time during the previous three months by patients who satisfied the Rome II criteria for irritable bowel disorder (IBS) or functional constipation (FC)

\begin{tabular}{|c|c|c|c|c|c|c|}
\hline \multirow[b]{3}{*}{ Symptom } & \multicolumn{3}{|c|}{ IBS } & \multicolumn{3}{|c|}{ FC } \\
\hline & Total (\%) & Male (\%) & Female (\%) & Total (\%) & Male (\%) & Female (\%) \\
\hline & 103 & 18 & 85 & 82 & 15 & 67 \\
\hline Straining during a bowel movement & 89.3 & 88.9 & 89.4 & 81.7 & 73.3 & 83.6 \\
\hline Hard or lumpy stools & 86.4 & 77.8 & 88.2 & 82.9 & 80.0 & 83.6 \\
\hline Abdominal fullness, bloating or swelling & $77.7^{*}$ & 50.0 & 83.5 & 52.4 & 26.7 & 58.2 \\
\hline Feeling of incomplete emptying after a BM & 76.7 & 83.3 & 75.3 & 72.0 & 53.3 & 76.1 \\
\hline A sensation that stool cannot be passed & 76.7 & 72.2 & 77.6 & 72.0 & 66.7 & 73.1 \\
\hline Fewer than three BMs per week & 57.3 & 55.6 & 57.6 & 46.3 & 33.3 & 49.3 \\
\hline A need to press on or around your anus & 51.5 & 27.8 & 56.5 & 39.0 & 40.0 & 38.8 \\
\hline Having to rush to the toilet to have a BM & $38.8^{*}$ & 33.3 & 40.0 & 9.8 & 13.3 & 9.0 \\
\hline Loose, mushy or watery stools & $37.9^{*}$ & 38.9 & 37.6 & 0.0 & 0.0 & 0.0 \\
\hline Passing mucus during a BM & $32.0^{*}$ & 22.2 & 34.1 & 14.6 & 0.0 & 17.9 \\
\hline More than three BMs per day & 10.7 & 5.6 & 11.8 & 14.4 & 6.7 & 9.0 \\
\hline
\end{tabular}

*z-test $P<0.05$ IBS total versus FC total (adjusted for multiple comparisons). BM Bowel movement 
Diary

Of the 220 patients, 185 provided sufficient data in the Bristol Stool Form Scale to estimate the WGTT. For diary weeks 1 and 4, WGTTs were similar for patients who selfreported constipation and those who fulfilled the Rome II criteria for FC or IBS. Results from week 1 are presented in Table 4. WGTTs were shorter in males than in females $(\mathrm{P}<0.05)$, and 'slow transit' time (2 SD above the norm) was observed in $22.2 \%$ (41 of 185 ) of patients (male $26.8 \%$ [11 of 41] and female 20.8\% [30 of 144]). For males, 'slow transit' was observed in $33.3 \%$ of those who self-reported constipation, $38.5 \%$ with FC and $35.3 \%$ with IBS. For females, 'slow transit' was calculated in $22.0 \%$ of those who self-reported constipation, 29.4\% with FC and 19.2\% with IBS. Differences between the sexes were not significant.

During the four-week diary period, 191 patients used medication (including herbal and homeopathic remedies), an average of 29.9 times per patient (range one to 83, SD 21.7). Of the 162 different constipation treatments mentioned by these patients, the most often used were, 'bulk-forming agents' (eg, Metamucil [Proctor \& Gamble, Canada] 826 times; Kellogg's All-Bran [USA] 763 times; Prodiem Plain/Plus [Novartis Consumer Health Canada Inc] 355 times; Kelloggs's Bran Flakes/Buds 257 times); 'stimulant laxatives' (eg, Senokot [Purdue Frederick, USA] 316 times); 'stool softeners' (eg, docusate sodium 254 times) and 'fruit derivatives' (eg, prune juice or nectar/ prunes 248 times). The patients rated $49.8 \%$ of the doses taken as satisfactory, $18.4 \%$ as 'neither satisfactory nor dissatisfactory' and $31.8 \%$ as 'very or somewhat dissatisfactory'.

\section{DISCUSSION}

We have demonstrated that many patients whose presenting complaint is constipation, or for whom a problem of constipation is elicited during a visit to their family physician, do not fit the Rome II diagnostic criteria for FC. Nearly half of the sample satisfied the Rome II IBS criteria (46.8\%) and only $37.3 \%$ fulfilled the FC criteria. Thirtyfive patients (15.9\%) met neither criteria and may have suffered from other bowel or anorectal ailments. More patients younger than 65 years of age had IBS than FC, but FC was more common in the elderly subgroup.
TABLE 3

Comorbidity of subjects who fulfilled the Rome II criteria for irritable bowel syndrome (IBS) or functional constipation (FC)

\begin{tabular}{lccc}
\hline & $\begin{array}{c}\text { Total } \\
\mathbf{n}\end{array}$ & $\begin{array}{c}\text { Rome II-IBS } \\
\mathbf{n}(\%)\end{array}$ & $\begin{array}{c}\text { Rome II-FC } \\
\mathbf{n}(\%)\end{array}$ \\
\hline Medications for pain & ${ }^{*} 97$ & $48(46.6)$ & $37(45.1)$ \\
Medication for depression & 34 & $18(17.4)$ & $12(14.6)$ \\
Cancer & 16 & $8(7.8)$ & $2(2.4)$ \\
\hline
\end{tabular}

*In the past three months (medications included acetaminophen/ caffeine/codeine phosphate [Tylenol-3; Janssen Ortho, McNeil Consumer Healthcare, Canada], Tylenol with codeine [Janssen Ortho], acetaminophen/oxycodone hydrochloride [Percocet; Dupont Pharma, Canada], morphine, fentanyl [Duragesic, Janssen Ortho, Canada] or other narcotic)

Far more IBS patients than FC patients complained of loose, mushy or watery stools, and having to rush to the toilet to have a bowel movement. Because the Rome II criteria for FC exclude those who have diarrhea, it is not surprising that patients with IBS are more likely to have such features. Indeed, this information can serve as a distinguishing point in constipated patients and should be sought in the patient's history. However, it should be remembered that $77.7 \%$ of the patients in our study defined as having IBS were taking laxatives to treat constipation. Thus, the role of laxatives in such patients requires consideration in individual cases.

Probert et al (2) emphasized the difficulty in reconciling patient's complaints of constipation with diagnostic criteria and physiological observation. Our finding that most primary care patients who self-report or fit the Rome II constipation criteria have a normal estimated WGTT confirms previous observations $(2,11,13)$. Less than one-quarter of the patients in our sample had 'slow transit' time, but this is difficult to interpret because $87 \%$ of the subjects used medications or other remedies to treat their constipation during the diary period. As was observed in an earlier population study (10), the male subjects had shorter estimated transit times than females. Symptom-based criteria (Rome II)

\section{TABLE 4}

Whole gut transit times (WGTT), estimated from week 1 of a diary kept by patients who self-reported constipation, and those who met the Rome II criteria for irritable bowel syndrome (IBS) or functional constipation (FC)

\begin{tabular}{|c|c|c|c|c|c|c|}
\hline \multirow[b]{3}{*}{ Symptom } & \multicolumn{6}{|c|}{ WGTT (h) } \\
\hline & \multicolumn{2}{|c|}{ All } & \multicolumn{2}{|c|}{ Males } & \multicolumn{2}{|c|}{ Females } \\
\hline & $\mathbf{n}$ & Mean \pm SD & $\mathbf{n}$ & Mean \pm SD & $\mathbf{n}$ & Mean \pm SD \\
\hline Self-report constipation* & 165 & $79.3 \pm 27.7$ & 33 & $67.6 \pm 18.1^{\dagger}$ & 132 & $82.2 \pm 29.0$ \\
\hline Rome II FC & 64 & $85.9 \pm 24.9$ & 13 & $72.2 \pm 15.7^{\dagger}$ & 51 & $89.3 \pm 25.7$ \\
\hline Rome II IBS & 90 & $77.4 \pm 28.8$ & 17 & $67.8 \pm 19.0^{\dagger}$ & 73 & $79.7 \pm 30.3$ \\
\hline
\end{tabular}

Note: Of the 220 participants 185 provided sufficient data to calculate transit times. ${ }^{*}$ In the past three months; ${ }^{\dagger} P<0.05$ males versus females 
reduced the number of patients self-reporting constipation in the questionnaire from 196 to 82 . However, the criteria did not reveal a significantly higher number of patients with 'slow transit'. Nevertheless, a diary employing the Bristol Stool Form Scale is useful to ascertain the nature of the bowel habit and may improve clinical judgment as to whether a person is constipated (2).

Comorbidity due to cancer and the use of medication for pain or depression was common in the patients studied, with $46 \%$ of patients with IBS and $45 \%$ of patients with FC consuming narcotic analgesics. Thus, it is necessary to take a careful medical history that specifically includes information about potentially constipating drugs before diagnosing IBS and FC, and initiating treatment.

Overall, $86.5 \%$ of patients were consuming various remedies or medications to treat their constipation. Rates of dissatisfaction with diet-related treatments (bran, fibre, cereals, fruits and derivatives, and herbs) and medications (psyllium, stool softeners, osmotics, lubricants and stimulant laxatives) were similar, at $32.5 \%$ and $31.8 \%$ of doses, respectively. Only half of these remedies were rated as satisfactory by the patients, demonstrating a need for more innovative therapies, better prescribing habits or improved patient adherence.

Results of our study are constrained by the low number of willing family physicians and the lack of randomization in patient recruitment, introducing the issue of representation and the possibility of a selection bias, respectively.

\section{REFERENCES}

1. Irvine EJ, Ferrazzi S, Thompson WG, Pare P, Rance L. Health-related quality of life (HRQOL) in subjects with constipation, defined by Rome II criteria and self-reported constipation. Can J Gastroenterol 2001;15(Suppl A):58A. (Abst)

2. Probert CSJ, Emmett PM, Cripps HA, Heaton KW. Evidence for the ambiguity of the term constipation: the role of irritable bowel syndrome. Gut 1994;35:1455-8.

3. Pare P, Ferrazzi S, Thompson WG, Irvine EJ, Rance L. An epidemiological survey of constipation in Canada: Definitions, rates, demographics and predictors of health care seeking. Am J Gastroenterol 2001;96:3130-7.

4. Sonnenberg A, Koch TR. Physician visits in the United States for constipation: 1958 to 1986. Dig Dis Sci 1989;34:606-11.

5. Statistics Canada. CANSIM II, Table 051-0001. <http://www.statcan.ca/english/Pgdb/People/Population/demo10a.htm> (Version current at August 25, 2001)

6. Heaton KW, O'Donnell LJD. An office guide to whole gut transit time. Patient's recollection of their stool form. J Clin Gastroenterol 1994;19:28-30.

7. Lewis SJ, Heaton KW. Stool form scale as a useful guide to intestinal transit time. Scand J Gastroenterol 1997;32:920-4.

8. Heaton KW, Ghosh S, Braddon FEM. How bad are the symptoms and bowel dysfunction of patients with the irritable bowel syndrome? A prospective, controlled study with emphasis on stool form. Gut 1991;32:73-9.

9. O’Donnell LJD, Virjee J, Heaton KW. Detection of pseudo-diarrhoea
We observed similar female to male ratios for IBS and FC. In previous population-based studies, females have had almost twice the prevalence of constipation or IBS of males $(14,15)$. In one other primary care population, the female to male ratio for IBS was 5:1 (16). The lack of such a sex difference in our IBS and FC groups may be due to the nonrandom nature of the sample. However, the study's natural setting and relevance to everyday clinical practice balance the weakness. The completion rates of the questionnaire and week 1 of the diary by the patients were satisfactory, at $70.7 \%$ and $67.8 \%$, respectively. Subsequent weekly completion rates of the diary were also high.

\section{SUMMARY}

We have confirmed that many patients visiting their family physicians with constipation are not functionally constipated at the time and that nearly half fit the Rome II diagnostic criteria for IBS. Estimated WGTTs were normal in most subjects and failed to differentiate between patients with FC and those with IBS. Many IBS patients have diarrhea that may be due in part to laxative use. Therefore, careful history-taking is essential to avoid inappropriate prescribing. Moreover, while IBS requires limited or no investigation if symptoms have been present for some time, or previously investigated, severe constipation or the presence of alarm symptoms (bleeding, fever, weight loss) may require further study.

by simple clinical assessment of intestinal transit rate. BMJ 1990;300:439-40.

10. Probert CJ, Emmett PM, Heaton KW. Intestinal transit time in the population calculated from self made observations of defecation. J Epidemiol Community Health 1993;47:331-3.

11. Chaussade S, Khyari A, Roche H, et al. Determination of total and segmental colonic transit time in constipated patients. Results in 91 patients with a simplified method. Dig Dis Sci 1989;34:1168-72.

12. Drossman DA, Corazziari E, Talley NJ, Thompson WG,

Whitehead WE. Appendix B. The Rome II Modular Questionnaire. In: Drossman DA, Corazziari E, Talley NJ, Thompson WG,

Whitehead WE, eds. The Functional Gastrointestinal Disorders. McLean: Degnon, 2000:670-88.

13. Turnbull GK, Barton CI, Lennard-Jones JF. Radiological studies of rectal evacuation in adults with idiopathic constipation. Dis Colon Rectum 1988;31:190-7.

14. Thompson WG, Irvine EJ, Pare P, Ferrazzi S, Rance L. Functional gastrointestinal disorders in Canada: first population-based survey using Rome II criteria with suggestions for improving the questionnaire. Dig Dis Sci 2002;47:225-35.

15. Drossman DA, Li Z, Andruzzi E, et al. U.S. householder survey of functional gastrointestinal disorders: prevalence, sociodemography and health impact. Dig Dis Sci 1993;38:1569-80.

16. Thompson WG, Heaton KW, Smyth T, Smyth C. Irritable bowel syndrome in general practice: prevalence, characteristics, and referral. Gut 2000;46:78-82. 


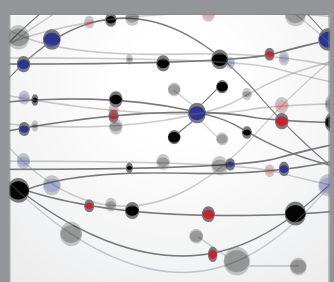

The Scientific World Journal
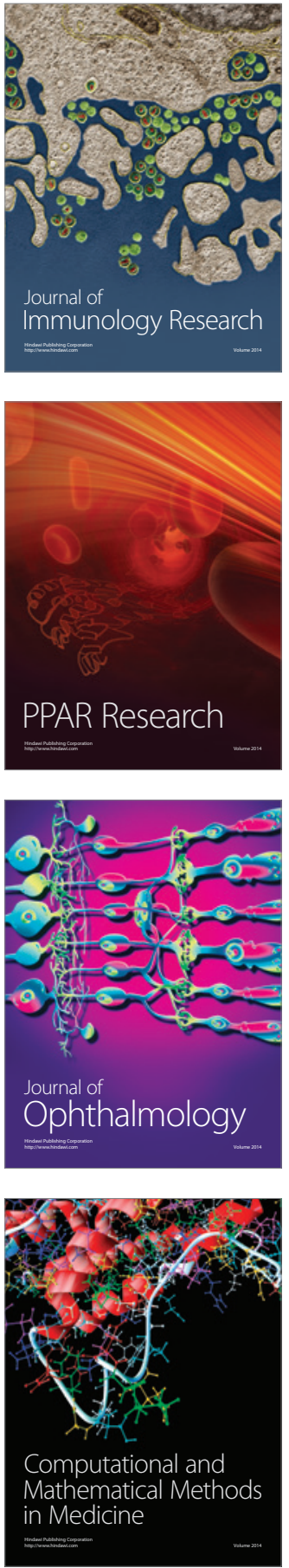

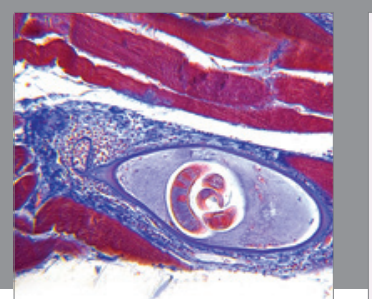

Gastroenterology Research and Practice

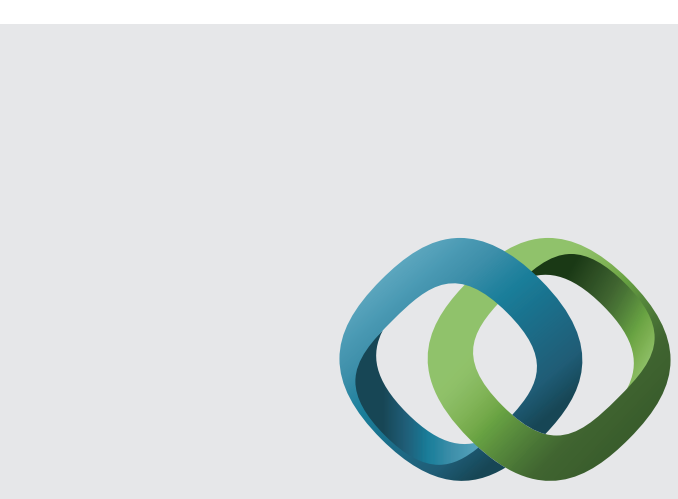

\section{Hindawi}

Submit your manuscripts at

http://www.hindawi.com
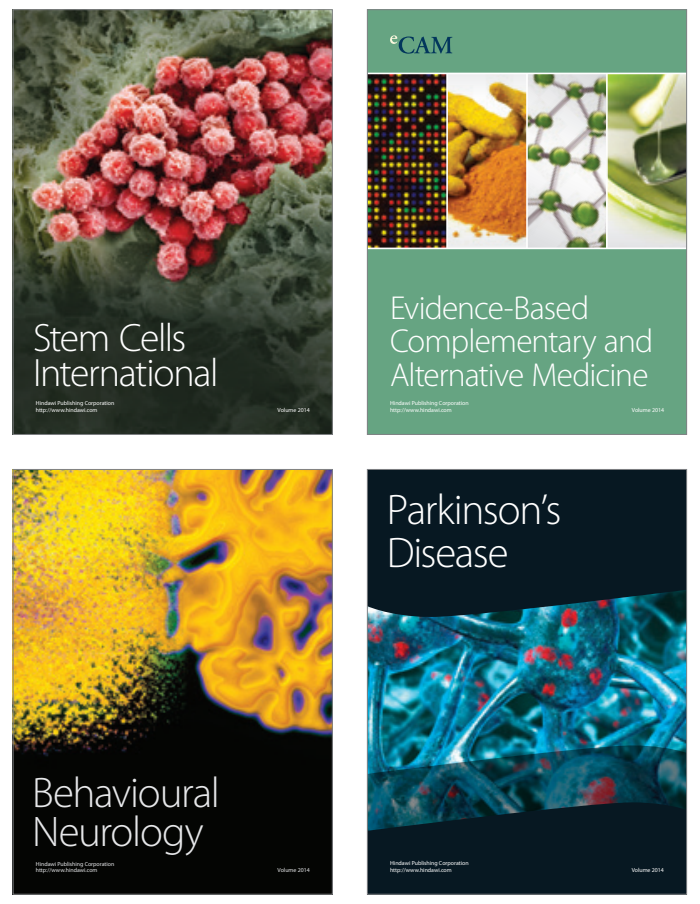
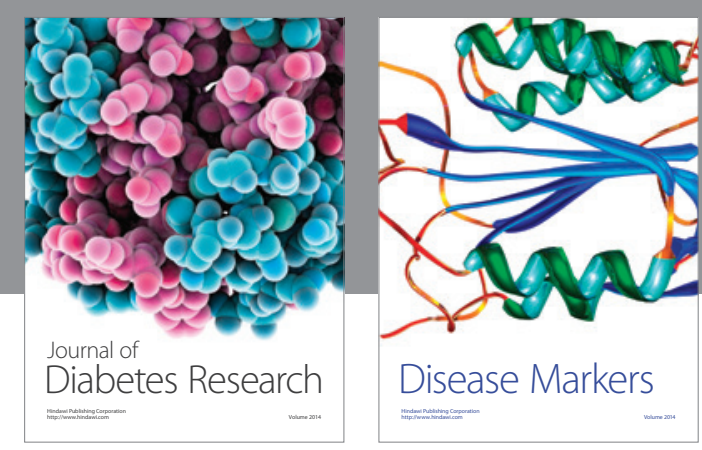

Disease Markers
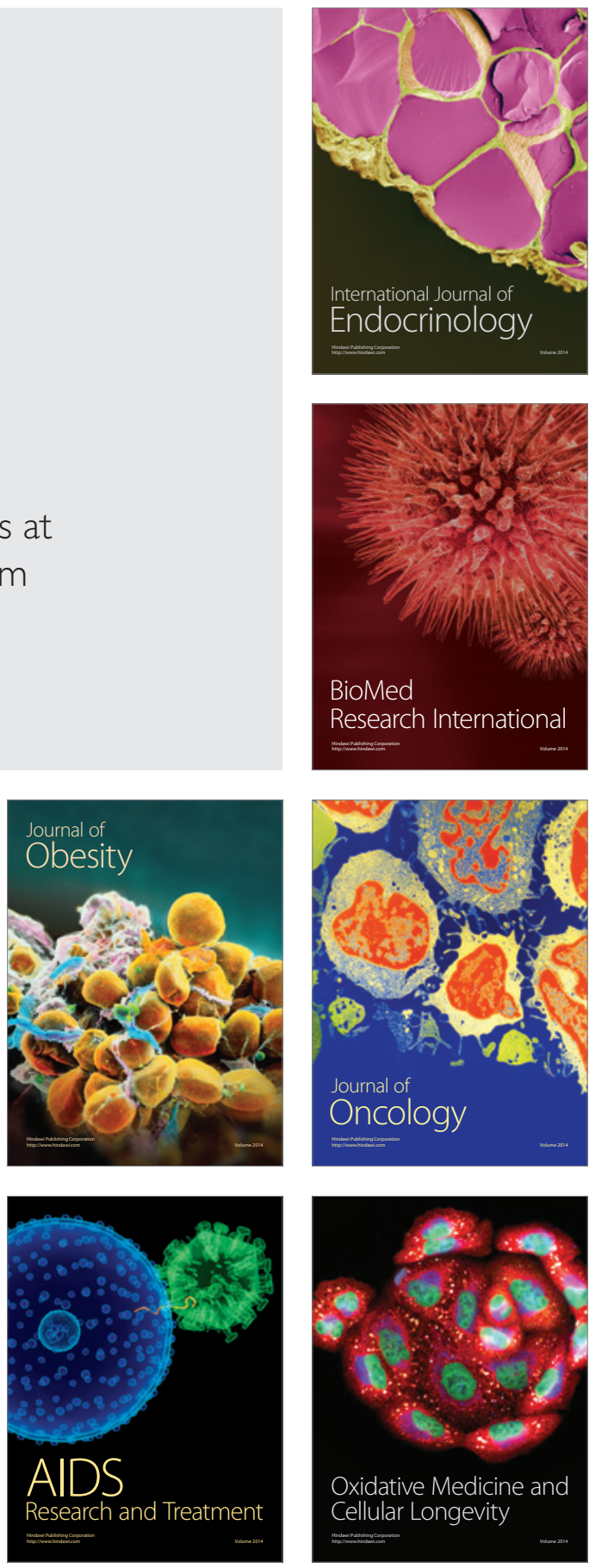